\title{
The GH secretagogues ipamorelin and GH-releasing peptide-6 increase bone mineral content in adult female rats
}

\author{
J Svensson ${ }^{1}$, S Lall ${ }^{2}$, S L Dickson ${ }^{2}$, B-Å Bengtsson ${ }^{1}$, J Rømer ${ }^{3}$, \\ I Ahnfelt-Rønne ${ }^{3}$, C Ohlsson ${ }^{1}$ and J-O Jansson ${ }^{1}$ \\ ${ }^{1}$ Research Centre for Endocrinology and Metabolism, Sahlgrenska University Hospital, Göteborg, Sweden \\ ${ }^{2}$ Department of Physiology, University of Cambridge, Cambridge, UK \\ ${ }^{3}$ Health Care Discovery, Novo Nordisk A/S, Bagsvaerd, Denmark \\ (Requests for offprints should be addressed to J Svensson, Research Centre for Endocrinology and Metabolism, Gröna Stråket 8, Sahlgrenska University \\ Hospital, SE-41345 Göteborg, Sweden; Email: Johan.Svensson@medic.gu.se) \\ (J Svensson and S Lall have made an equal contribution to this paper)
}

\begin{abstract}
Growth hormone $(\mathrm{GH})$ is of importance for normal bone remodelling. A recent clinical study demonstrated that MK-677, a member of a class of GH secretagogues (GHSs), increases serum concentrations of biochemical markers of bone formation and bone resorption. The aim of the present study was to investigate whether the GHSs, ipamorelin (IPA) and GH-releasing peptide-6 (GHRP-6), increase bone mineral content (BMC) in young adult female rats. Thirteen-week-old female Sprague-Dawley rats were given IPA $(0.5 \mathrm{mg} / \mathrm{kg}$ per day; $n=7)$, GHRP-6 (0.5 mg/kg per day; $n=8)$, GH (3.5 mg/kg per day; $n=7)$, or vehicle administered continuously s.c. via osmotic minipumps for 12 weeks. The animals were followed in vivo by dual X-ray absorptiometry (DXA) measurements every 4th week. After the animals were killed, femurs were analysed in vitro by mid-diaphyseal peripheral quantitative computed tomography (pQCT) scans. After this, excised femurs and vertebrae L6 were analysed by the use of Archimedes' principle and by determinations of ash weights. All treatments increased body weight and total tibial and vertebral BMC measured by DXA in vivo
\end{abstract}

compared with vehicle-treated controls. However, total BMC corrected for the increase in body weight (total BMC:body weight ratio) was unaffected. Tibial area bone mineral density (BMD, BMC/area) was increased, but total and vertebral area BMDs were unchanged. The pQCT measurements in vitro revealed that the increase in the cortical BMC was due to an increased cross-sectional bone area, whereas the cortical volumetric BMD was unchanged. Femur and vertebra L6 volumes were increased but no effect was seen on the volumetric BMDs as measured by Archimedes' principle. Ash weight was increased by all treatments, but the mineral concentration was unchanged. We conclude that treatment of adult female rats with the GHSs ipamorelin and GHRP-6 increases BMC as measured by DXA in vivo. The results of in vitro measurements using pQCT and Archimedes' principle, in addition to ash weight determinations, show that the increases in cortical and total BMC were due to an increased growth of the bones with increased bone dimensions, whereas the volumetric BMD was unchanged.

Journal of Endocrinology (2000) 165, 569-577

\section{Introduction}

Both clinical and animal studies have demonstrated that growth hormone $(\mathrm{GH})$ is important for normal bone modelling and remodelling (Bouillon 1991, Eriksen et al. 1996, Ohlsson et al. 1998). In young adult rats, GH treatment increases bone mass by increased longitudinal growth at the growth plate and by increased subperiosteal bone deposition (Ohlsson et al. 1998). In old male rats, 80 days of $\mathrm{GH}$ treatment increased cortical bone formation mainly through increased subperiosteal bone formation (Andreassen et al. 1995). In young and in old rats, GH treatment increased cortical mechanical strength, mainly as a result of an increase in bone dimensions (Jørgensen et al.
1991, Andreassen et al. 1995). In primates, GH but not insulin-like growth factor (IGF)-I given to female monkeys for 7 weeks increased bone formation as measured with mineral apposition rate, and the bone formation rate (Sass et al. 1997). In GH-deficient (GHD) humans, long-term GH treatment increased total bone mineral content (BMC) and area bone mineral density (BMD) in several weight-bearing skeletal locations (Johannsson et al. 1996). Studies to date have not shown any impressive effect of GH on bone mass in non-GHD subjects.

The mechanism for the stimulatory effect of $\mathrm{GH}$ on the amount of bone is not fully understood. Normal bone metabolism is regulated by a balance between bone formation caused by osteoblasts and bone resorption caused 
by osteoclasts. Osteoblastic cells, in addition to being directly responsible for bone formation, control bone resorption by regulating the proliferation, differentiation and recruitment of osteoclast progenitors (Takahashi et al. 1988). Human osteoblast-like cells express functional GH receptors and $\mathrm{GH}$ has been shown to exert an anabolic effect on the osteoblasts (Kassem et al. 1993, Nilsson et al. 1995). These findings indicate a direct stimulatory effect of $\mathrm{GH}$ on bone formation.

Pituitary GH secretion is regulated by the stimulatory peptide GH-releasing hormone (GHRH) and the inhibitory peptide somatostatin (Frohman \& Jansson 1986). The new class of synthetic GH secretagogues (GHSs) that has been developed includes $\mathrm{GH}$-releasing peptides $(\mathrm{GH}-$ RPs) such as GHRP-2, GHRP-6 and hexarelin, and non-peptidyl oral GHSs such as MK-677 (Smith et al. 1998). A G protein-coupled receptor has been found to be a target for these substances (Howard et al. 1996). An endogenous ligand specific for the GHS receptor was recently described (Kojima et al. 1999). At the hypothalamic level, the GHSs stimulate GH secretion by activating arcuate nucleus GHRH neurones (Dickson \& Luckman 1997), resulting in increased release of GHRH into portal blood (Guillaume et al. 1994). The GHSs also stimulate GH secretion by a direct action at the pituitary level (Bowers et al. 1984), where the GHSs may act as functional antagonists of somatostatin action (Smith et al. 1998). The stimulatory effect on GH release seems to be persistent, as the GHRPs hexarelin and GHRP-2 have been reported to increase growth velocity in children with short stature/GHD (Laron et al. 1995, Mericq et al. 1998). In addition to $\mathrm{GH}$ release, most GHSs have been found to elicit a transient cortisol response (Svensson et al. 1998a). However, the novel GHS, ipamorelin, has not yet been found to stimulate glucocorticoid release (Raun et al. 1998).

The GHSs enhance the amplitude of the physiological GH pulses (Smith et al. 1998), whereas an s.c. injection of $\mathrm{GH}$ induces a bell-shaped curve of serum GH concentrations that are continuously high for more than $12 \mathrm{~h}$ (Oscarsson et al. 1997). Little is known about the effects on bone of an increase in the amplitude of endogenous pulsatile GH secretion. We have recently shown that short-term treatment of obese men with the oral GHS, MK-677, increases circulating biochemical markers of bone formation and bone resorption (Svensson et al. 1998b). The aim of the present study was to determine the effect of 12 weeks of treatment with the GHSs ipamorelin and GHRP-6 on bone mass in young adult female Sprague-Dawley rats.

\section{Material and Methods}

Animals

Female Sprague-Dawley rats $(n=30 ; 13$ weeks old, mean body weight $228 \mathrm{~g}$ at onset; obtained from BK Universal,
Stockholm, Sweden) were housed under standardised environmental conditions $\left(24-26{ }^{\circ} \mathrm{C}, 50-60 \%\right.$ relative humidity, artificial lighting on from 0500 to $1900 \mathrm{~h}$ ). The rats were given free access to water and to standard rat chow containing $0 \cdot 8 \%$ calcium and $0.6 \%$ phosphorus (BK Universal). All experimental procedures were carried out according to ethical guidelines for animal experimentation at the University of Göteborg.

\section{Study procedure}

Over a 12-week period, rats were infused s.c. with human $\mathrm{GH}(3.5 \mathrm{mg} / \mathrm{kg}$ per day; Norditropin; Novo Nordisk A/S, Copenhagen, Denmark; $n=7)$, GHRP-6 (0.5 mg/kg per day, Bachem, Bubendorf, Switzerland; $n=8)$, ipamorelin $(0.5 \mathrm{mg} / \mathrm{kg}$ per day; Novo Nordisk A/S; $n=7)$ or vehicle $(0.05 \%$ acetic acid in sterile $0.5 \%$ saline; $n=8)$ using osmotic minipumps (Alzet 2004; Alza Corp., Palo Alto, CA, USA). In vivo dual X-ray absorptiometry (DXA) measurements were performed at baseline and after 4,8 and 12 weeks of treatment. Before the DXA measurements, the rats were anaesthetised with a combination of ketamine $(1.8 \mathrm{ml} / \mathrm{kg}$; Ketalar, Park Davies, Morris Plains, $\mathrm{NJ}$, USA; $67 \mathrm{mg} / \mathrm{kg}$ ) and xylazine $(13 \mathrm{mg} / \mathrm{kg}$; Rompun, Bayer AG, Leverkusen, Germany) given i.p. During anaesthesia, the osmotic minipumps were removed and body weight and DXA measurements were performed, followed by implantation of new osmotic minipumps. Food intake was measured at baseline and after 4, 8 and 12 weeks of treatment by the use of metabolic cages. At the end of the experiment, rats were killed by decapitation and excised bones were stored in ethanol, then excised femurs were analysed by using peripheral quantitative computed tomography (pQCT). After this, femurs and vertebrae L6 were analysed by the use of Archimedes' principle and by determinations of ash weights.

\section{Dual X-ray absorptiometry}

BMC (in $\mathrm{g}$ ) and area BMD (in $\mathrm{g} / \mathrm{cm}^{2}$ ) were measured in vivo by DXA (pDEXA Sabre; Norland Corp., Fort Atkinson, WI, USA). The software Sabre Research (version 3.6) was used. Total body BMC and area BMD $(\mathrm{BMC} / \mathrm{area})$ were measured from the lower level of thoracic vertebra 9 to the inferior level of the first tail vertebra (the maximal scan area of the DXA). BMC and area BMD of tibia were measured from the knee joint to the joint between tibia and calcaneus (and thus these measurements also include fibula). BMC and area BMD of vertebra were measured from the superior level of lumbar vertebra 3 to the inferior level of lumbar vertebra 6 (L3-L6). The interassay coefficients of variation (CVs) for the DXA measurements were less than $4 \%$.

\section{Femur length and vertebral body L6 height}

The length of femurs was determined in vitro with DXA. The femurs were placed in an anatomical position (facing 
Table 1 Body weight and bone dimensions after 12 weeks of treatment of female Sprague-Dawley rats with IPA, GHRP-6, GH or vehicle. All values are presented as the mean (S.E.M.)

\begin{tabular}{|c|c|c|c|c|}
\hline & $\begin{array}{l}\text { Vehicle } \\
(n=8)\end{array}$ & $\begin{array}{l}\text { IPA } \\
(n=7)\end{array}$ & $\begin{array}{l}\text { GHRP-6 } \\
(n=8)\end{array}$ & $\begin{array}{l}\text { GH } \\
(n=7)\end{array}$ \\
\hline \multicolumn{5}{|l|}{ Variable } \\
\hline Body weight at baseline $(\mathrm{g})$ & $234(8)$ & $223(9)$ & $230(8)$ & $223(8)$ \\
\hline Body weight after 12 weeks of treatment $(\mathrm{g})$ & $320(8)$ & $340(9)^{* *}$ & $354(5)^{* *}$ & $338(5)^{* *}$ \\
\hline Body weight increase (\%) & $37 \cdot 6(3 \cdot 5)$ & $52 \cdot 9(5 \cdot 9)^{* *}$ & $55 \cdot 1(4 \cdot 9)^{* *}$ & $53 \cdot 3(5 \cdot 8)^{* *}$ \\
\hline Femur length $(\mathrm{mm})$ & $37 \cdot 2(0 \cdot 4)$ & $37 \cdot 9(0 \cdot 2)$ & $38 \cdot 4(0 \cdot 2)^{*}$ & $37 \cdot 8(0 \cdot 2)$ \\
\hline Vertebral body L6 height (mm) & $7.67(0.07)$ & $7 \cdot 82(0 \cdot 10)$ & $7 \cdot 85(0 \cdot 05)$ & $7 \cdot 74(0 \cdot 08)$ \\
\hline
\end{tabular}

For body weight after 12 weeks of treatment, $P$-values (compared with vehicle) were calculated by two-way ANOVA of the percent change from baseline, followed by Student-Newman-Keuls post hoc test. $P$ values for differences in femur length and vertebral body L6 height were calculated by one-way ANOVA followed by Student-Newman-Keuls post hoc test.

${ }^{*} P<0 \cdot 05,{ }^{* *} P<0 \cdot 01$, compared with vehicle.

anteriorly) in a Petri dish. The length of each femur was determined by lining up the cursors on the screen with the trochanter at the top and the lateral condyle at the bottom of the femur. The distance between the cursors was measured by a ruler tool in the software. The $\mathrm{CV}$ was less than $1 \%$.

The body of vertebra L6 was cleaned of all soft tissue, including the intravertebral discs. Then the height of vertebral body L6 was determined at the middle of the anterior surface using a micrometer. The $\mathrm{CV}$ was less than $1 \%$.

\section{Peripheral quantitative computed tomography}

Tomographic measurements were performed using the Stratec pQCT XCT Research M (Norland Corp.) specifically modified for use on small bone specimens (software version 5.4B; resolution $70 \mu \mathrm{m}$ (Windahl et al. 1999)). Cortical volumetric BMD (BMC/volume), the cortical cross-sectional area and cortical BMC were determined by mid-diaphyseal pQCT scans of excised femurs. The interassay CVs for the pQCT measurements were less than $3 \%$.

\section{Archimedes' principle and ash weights}

The whole femurs and vertebrae were immersed in distilled water and submitted to vacuum for at least $10 \mathrm{~min}$ to remove trapped air bubbles. Then the wet weight and the weight of the bones in distilled water were determined. After the bones had been defatted in acetone for 2 days followed by freeze-drying for 3 days, the dry defatted weight was determined (Sandstedt et al. 1996). The (real) volume was calculated as (dry defatted weight - weight in distilled water)/density of distilled water. The (real) volumetric BMD was calculated as dry defatted weight/(real) volume of the bone. The ash weight (mineral weight) was determined after incineration in a muffle oven at $105^{\circ} \mathrm{C}$ for $2 \mathrm{~h}$, followed by $580{ }^{\circ} \mathrm{C}$ for $24 \mathrm{~h}$. The mineral concentration was calculated by dividing mineral weight by dry defatted weight.

\section{Metabolic cages}

The rats were housed for 2 days in metabolic cages at baseline and after 4, 8 and 12 weeks of treatment (before the DXA measurements at each time point). Water and powdered food were freely available and food intake was measured daily.

\section{Statistics}

All the descriptive statistical results that are presented are given as the arithmetic mean and standard error of the mean (s.E.M.). Bartlett's test was performed to evaluate if data were normally distributed. For skewly distributed data (cortical BMD, cross-sectional cortical bone area and cortical BMC obtained from the pQCT measurements of femurs in vitro), a logarithmic transformation was performed before the analysis of between-group differences. For body weight and for data obtained from DXA measurements in vivo, a two-way analysis of variance (ANOVA) of the percent change from baseline were performed with time and treatment as the independent variables, followed by Student-Newman-Keuls post hoc test. The data obtained from in vitro measurements (pQCT, Archimedes' principle, ash weight) were analysed by a one-way ANOVA with treatment as the independent variable, followed by Student-Newman-Keuls post hoc test. A two-tailed $P<0 \cdot 05$ was considered significant.

\section{Results}

Body weight, food intake and dimensions of bones

Baseline body weight was similar in all study groups. However, the increase in body weight was larger after all 
a) Total BMC

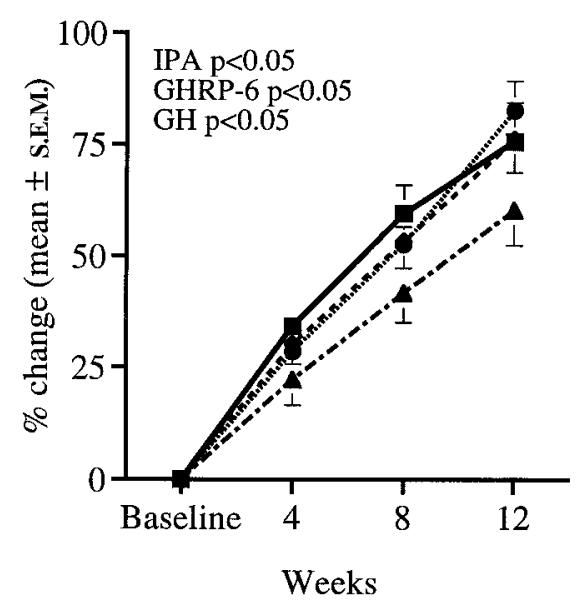

b) Tibia BMC

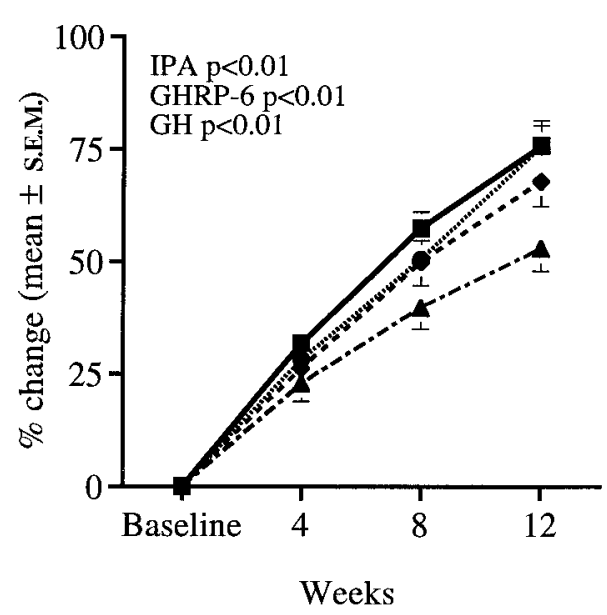

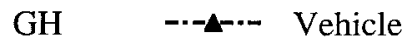

c) Vertebra BMC $\left(\mathbf{L}_{3}-\mathbf{L}_{6}\right)$

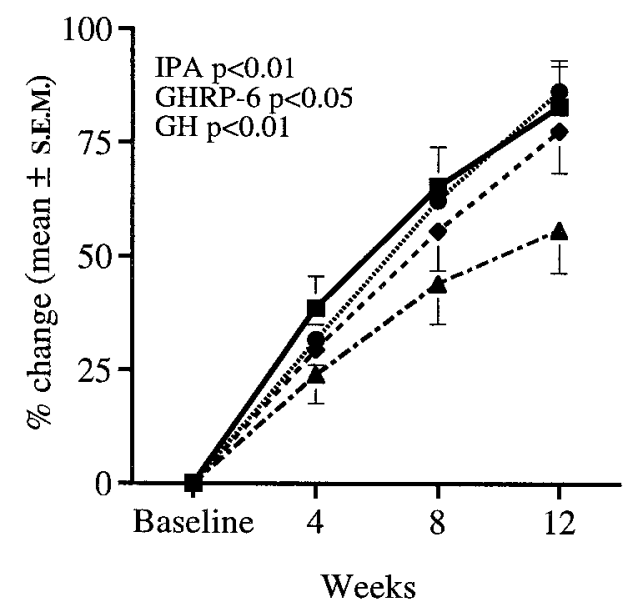

d) Total BMC/body weight ratio

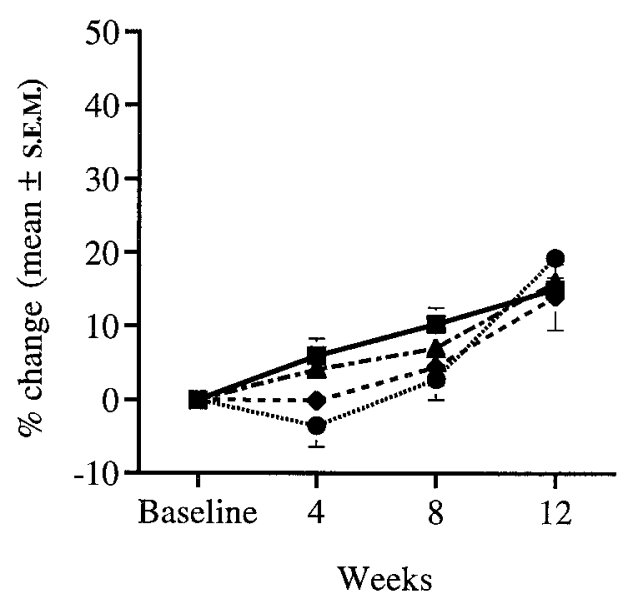

Figure 1 Percentage change in (a) total body BMC, (b) tibia BMC, (c) vertebral BMC (L3-L6), and (d) total BMC/body weight ratio during 12 weeks of treatment of female Sprague-Dawley rats with IPA, GHRP-6, $\mathrm{GH}$ or vehicle. The BMC values were measured by DXA in vivo. The $P$ values shown (compared with vehicle) were calculated by two-way ANOVA of the percent change from baseline, followed by Student-Newman-Keuls post hoc test.

treatments than after vehicle (Table 1). Food intake was unchanged (data not shown). Femur length was increased in the GHRP-6-treated rats compared with vehicletreated rats, but that in the GH- and IPA-treated rats was not statistically changed (Table 1). The height of vertebral body L6 was unchanged (Table 1).
DXA measurements of $B M C$ in vivo

There were no differences at baseline in any of the bone parameters measured by DXA (data not shown). As measured by DXA in vivo, both of the GHSs (IPA and GHRP-6) and GH increased total, tibial and vertebral BMCs compared with vehicle (Fig. 1a-c). However, 
a) Total BMD

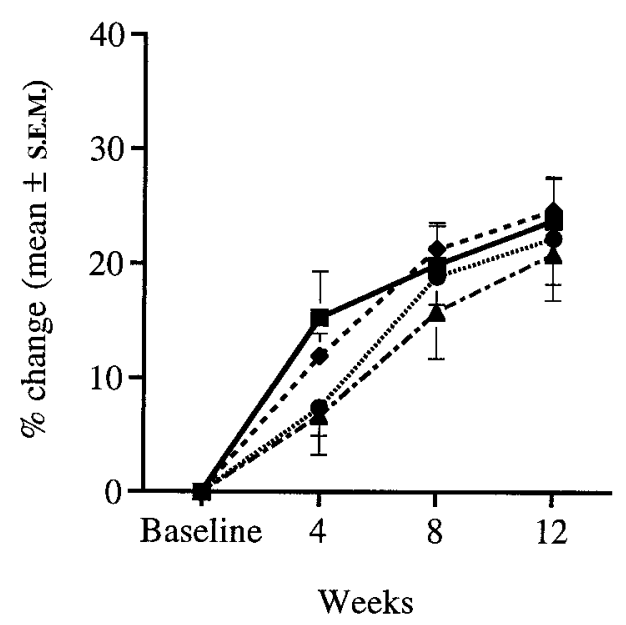

c) Vertebra BMD $\left(\mathbf{L}_{3}-\mathbf{L}_{6}\right)$

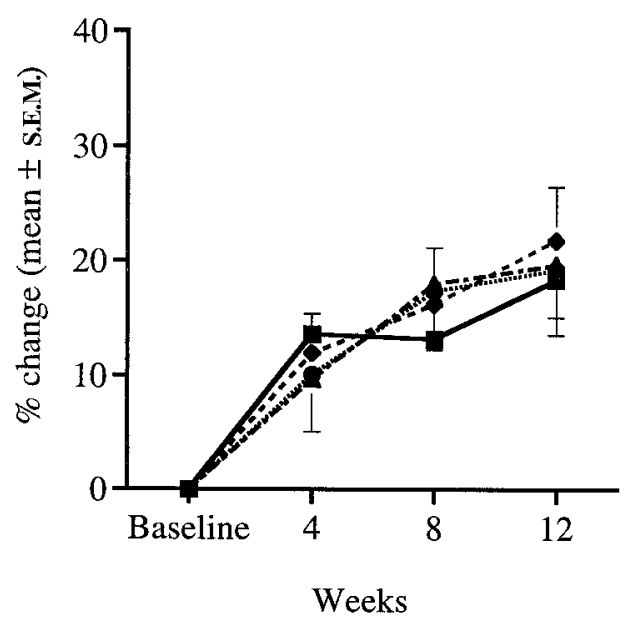

b) Tibia BMD

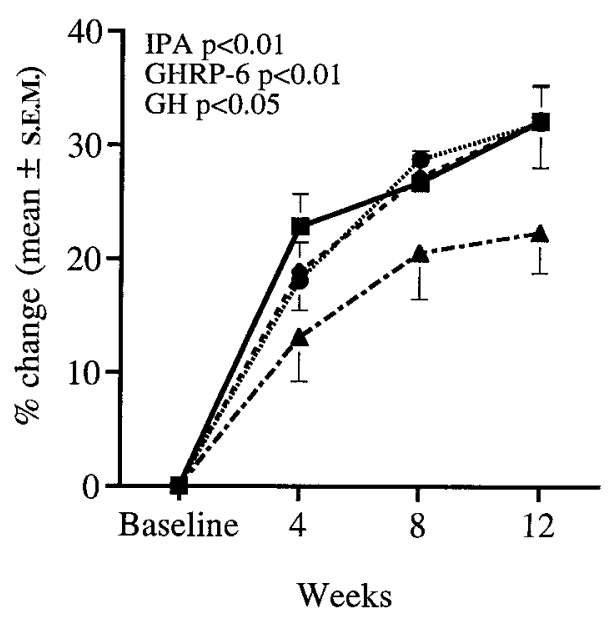

Figure 2 Percent change in (a) total body BMD, (b) tibia BMD, and (c) vertebral BMD (L3-L6) as measured by DXA in vivo during 12 weeks of treament of female Sprague-Dawley rats with IPA, GHRP-6, GH or vehicle. No effect was found on total or vertebral BMD, but all treatments induced a significant increase in tibia BMD compared with the vehicle-treated controls. The $P$ values shown (compared with vehicle) were calculated by two-way ANOVA of the percent change from baseline, followed by Student-Newman-Keuls post hoc test.

when the increase in total $\mathrm{BMC}$ was corrected for the increase in body weight (total BMC/body weight ratio), the increase in total BMC lost statistical significance (Fig. 1d). Spine and tibia BMC also were unchanged when corrected for body weight (data not shown).

All substances increased the tibial area BMD, as measured by DXA, but no significant effect was seen on total and vertebral area BMDs (Fig. 2a-c).
Effects on cortical bone as measured using $p Q C T$

Mid-diaphyseal pQCT scans of excised right femurs demonstrated that the cortical BMC was increased in the IPA and GH groups (IPA $P<0 \cdot 05$ compared with vehicle; GH $P<0 \cdot 05$ compared with vehicle; GHRP-6 $P=0 \cdot 06$ compared with vehicle; Table 2). The increase in middiaphyseal cortical BMC was due to an increase in 
Table 2 Cortical BMD, cross-sectional cortical bone area and cortical BMC, as measured by mid-diaphyseal pQCT scans of femurs in vitro, after 12 weeks of treatment of female Sprague-Dawley rats with IPA, GHRP-6, GH or vehicle. All values are presented as the mean (S.E.M.)

\begin{tabular}{|c|c|c|c|c|}
\hline & $\begin{array}{l}\text { Vehicle } \\
(n=8)\end{array}$ & $\begin{array}{l}\text { IPA } \\
(n=7)\end{array}$ & $\begin{array}{l}\text { GHRP-6 } \\
(n=8)\end{array}$ & $\begin{array}{l}\mathbf{G H} \\
(n=7)\end{array}$ \\
\hline \multicolumn{5}{|l|}{ Variable } \\
\hline Cortical BMD $\left(\mathrm{mg} / \mathrm{mm}^{3}\right)$ & $1 \cdot 355(0.004)$ & $1 \cdot 355(0 \cdot 004)$ & $1 \cdot 348(0 \cdot 004)$ & $1 \cdot 357(0 \cdot 004)$ \\
\hline Cortical BMC $(\mathrm{mg} / \mathrm{mm})$ & $7 \cdot 46(0 \cdot 22)$ & $8.02(0.12)^{*}$ & $7 \cdot 82(0 \cdot 16)^{* *}$ & $8.04(0.09)^{*}$ \\
\hline
\end{tabular}

Between-group differences were calculated by one-way ANOVA followed by Student-Newman-Keuls post hoc test. ${ }^{*} P<0 \cdot 05,{ }^{* *} P=0 \cdot 06$, compared with vehicle.

Table 3 Results of in vitro measurements using Archimedes' principle and ash weight determinations after 12 weeks of treatment of female Sprague-Dawley rats with IPA, GHRP-6, GH or vehicle. All values are presented as the mean (S.E.M.)

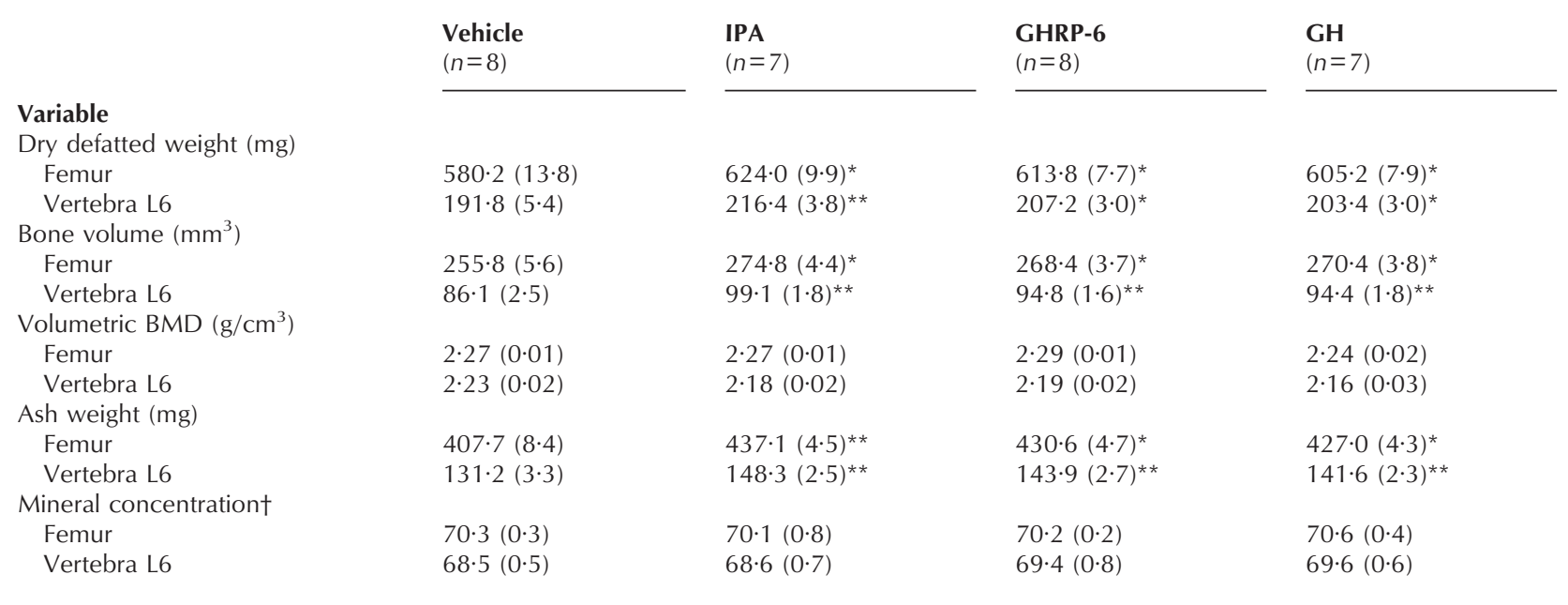

Between-group differences were calculated by one-way ANOVA followed by Student-Newman-Keuls post hoc test. †Ash weight/dry defatted weight.

${ }^{*} P<0 \cdot 05,{ }^{* *} P<0 \cdot 01$, compared with vehicle.

cross-sectional cortical bone area, whereas the cortical volumetric BMD was unaffected (Table 2).

\section{Archimedes' principle and ash weight}

The dry defatted weight of femur and vertebra L6 was increased by all treatments compared with the vehicletreated controls (Table 3). Measurements using Archimedes' principle showed that the volumes of femur and vertebra L6 were increased, but the volumetric BMD was unchanged (Table 3). Ash weight was increased for all treatments, but the mineral concentration, determined as ash weight per dry defatted weight, was unchanged (Table 3).

\section{Discussion}

The present study demonstrates that treatment with the GHSs, ipamorelin and GHRP-6, increases BMC in normal adult female rats. The results of several different measurements clearly indicate that the increases in cortical and total BMC were caused by increased bone volume, whereas the volumetric BMD was unchanged. The pQCT measurements of femurs in vitro showed an increase in cortical BMC that was due to an increase in the cross sectional bone area. Femur and vertebra L6 volumes were increased as measured by Archimedes' principle, whereas no effect was seen on the volumetric BMDs. Finally, ash weight (i.e. mineral content) was increased in all treatment groups, whereas the mineral concentration was unchanged.

In the present study, treatment with the GHSs and with $\mathrm{GH}$ itself increased body weight compared with vehicle, suggesting that the doses used and the route of administration of treatments were effective. The sustained increase in body weight in the GH-treated rats made it possible to rule out the possibility of species-dependent development of active antibodies against the human GH. This finding is supported by several previous studies 
demonstrating a sustained effect of human $\mathrm{GH}$ on BMC in rats (Andreassen et al. 1995, 1996). A desensitisation of the initial GH response has previously been observed after repeated GHS administration (Smith et al. 1998). In contrast, in the present study, a sustained increase in body weight and BMC was seen for IPA and GHRP-6, indicating that GHSs can also exert stimulatory effects in treatment prolonged over several months.

Total food intake was unaffected by both GHS and GH treatment in the present study. An acute increase in food intake has been observed after intracerebroventricular administration of GHSs (Locke et al. 1995, Okada et al. 1996), but in this study, as in a previous clinical study (Svensson et al. 1998a), no effect has been observed after prolonged systemic or oral administration of GHSs. GH administration is known to increase food efficiency in rats (weight gain/food weight (Verrat-Durebex et al. 1999)). Therefore, increased food efficiency due to increased circulating GH is a likely explanation for the increases in body weight induced by all treatments in this study.

GH treatment and GHS treatment increased tibia area BMD as measured by DXA in vivo in the present study. However, the pQCT measurements of femurs in vitro revealed an unaffected cortical volumetric BMD and the measurements using Archimedes' principle showed an unchanged total femur and vertebra L6 volumetric BMD. Other studies have also shown that long-term GH treatment increases area BMD as measured by DXA (Yeh et al. 1994, Ohlsson et al. 1998), but the volumetric BMD (BMC/volume), as measured by Archimedes' principle or pQCT (Jørgensen et al. 1991, Andreassen et al. 1995, Rosen et al. 1995), is unchanged. These findings could be explained by an overestimation of the increase in BMD by DXA. Area BMD (BMC/area) does not account for the bone thickness perpendicular to the two-dimensional DXA image. Therefore, when cortical bone mass is increased because of enhanced subperiosteal bone deposition, this itself may result in enhanced area BMD as measured by DXA.

The increases in BMCs were of a magnitude similar to that in body weight. In almost all studies in rats, GH administration has resulted in increased body weight (Ohlsson et al. 1998). It can not be excluded that the increase in BMC is due to increased mechanical load exerted on the skeleton by the increased body weight. However, administration of GH or IGF-I also increased subperiosteal bone formation under weightless conditions during space flight, and the amount of added bone was similar to that obtained by GH or IGF-I administration on the ground (Turner 1995, Bateman et al. 1998). Therefore, the present increase in bone dimensions is likely to be due to a direct effect of $\mathrm{GH}$ on total bone growth. This may be caused by a radial bone growth resulting from increased subperiosteal bone formation. GH has been shown to increase subperiosteal bone deposition in both young and old adult rats (Andreassen et al. 1995,
Ohlsson et al. 1998), and an increased cross-sectional cortical bone area was also seen in this study.

The present increase in bone volume may also have been due to linear bone growth derived from the growth plate. In rats, the growth plates first begin to close when the rats are very old (Ohlsson et al. 1998). For this reason, most studies have also found a small stimulatory effect on longitudinal growth in adult rats (Ohlsson et al. 1998). Therefore, it is likely that linear bone growth was also stimulated in our present study. The measurements of femur length and vertebral body L6 height only showed a significant increase for femur height in the GHRP-6treated rats. However, small stimulatory effects on linear bone growth may not have been detected statistically in the GH- and ipamorelin-treated groups, as a result of the study design (seven or eight rats in each group).

$\mathrm{GH}$ administered by osmotic minipumps induces a continuous increase in circulating $\mathrm{GH}$ concentrations, whereas the GHSs, also when administered continuously, increase the amplitude of the endogenous GH pulses (Huhn et al. 1993, Jaffe et al. 1993). Furthermore, it has been suggested that different subtypes of the recently cloned GHS receptor may exist and that different GHSs may differ in their binding affinity for the different subtypes (Ong et al. 1998). Despite these differences, the effects on body growth and BMC were similar for all treatments with the doses and the route of administration used in the present study. There are also non-peptidyl GHSs that produce a potent GH response after oral administration (Ankersen et al. 1998, Hansen et al. 1998, Smith et al. 1998). Further studies are needed to investigate whether orally administered non-peptidyl GHSs also increase BMC.

In a previous clinical study we found that a 2-month treatment with the GHS, MK-677, increases circulating markers of bone formation and resorption (Svensson et al. 1998b). We have now shown that treatment of female rats with the GHSs ipamorelin and GHRP-6 for 3 months increased BMC as measured by DXA in vivo. The results of in vitro measurements using $\mathrm{PQCT}$ and Archimedes' principle, in addition to the ash weight determinations, show that the increases in cortical and total BMC were due to an increased growth of the bones with increased bone dimensions, the volumetric BMD remaining unchanged.

\section{Acknowledgements}

This study was supported by Novo Nordisk A/S, the Swedish Medical Research Council (9894 and 11621), the British Medical Council (G 9521630), the Lundberg Foundation, the Bergvall Foundation, the Swedish Medical Society, the Göteborg Medical Society, and the Swedish Association Against Rheumatic Diseases.

Presented in part at the 1998 Growth Hormone Research Society (GRS) Conference, San Francisco, USA, September 1998. 


\section{References}

Andreassen T, Jørgensen P, Flyvberg A, Ørskov H \& Oxlund H 1995 Growth hormone stimulates bone formation and strength of cortical bone in aged rats. Journal of Bone and Mineral Research $\mathbf{1 0}$ 1057-1067.

Andreassen T, Melsen F \& Oxlund H 1996 The influence of growth hormone on cancellous and cortical bone of the vertebral body in aged rats. Journal of Bone and Mineral Research 11 1094-1102.

Ankersen M, Johansen NL, Madsen K, Hansen BS, Raun K, Nielsen KK, Thøgersen H, Hansen TK, Peschke B, Lau J, Lundt BF \& Andersen PH 1998 A new series of highly potent growth hormonereleasing peptides derived from ipamorelin. Journal of Medicinal Chemistry 41 3699-3704.

Bateman TA, Zimmerman RJ, Ayers RA, Ferguson VL, Chapes SK \& Simske SJ 1998 Histomorphometric, physical, and mechanical effects of spaceflight and insulin-like growth factor-I on rat long bones. Bone 23 527-535.

Bouillon R 1991 Growth hormone and bone. Hormonal Research 36 49-55.

Bowers CY, Momany FA, Reynolds GA \& Hong A 1984 On the in vitro and the in vivo activity of a new synthetic hexapeptide that acts on the pituitary to specifically release growth hormone. Endocrinology 114 1537-1545.

Dickson SL \& Luckman SM 1997 Induction of c-fos mRNA in NPY and GRF neurones in the rat arcuate nucleus following systemic injection of the growth hormone secretagogue, GHRP-6. Endocrinology 138 771-777.

Eriksen E, Kassem M \& Langdahl B 1996 Growth hormone, insulinlike growth factors and bone remodelling. European Journal of Clinical Investigation 26 525-534.

Frohman L \& Jansson J-O 1986 Growth hormone-releasing hormone. Endocrine Reviews 7 223-253.

Guillaume V, Magnan E, Cataldi M, Dutour A, Sauze N, Renard M, Razafindraibe H, Conte-Devolx B, Deghenghi R, Lenaerts V \& Oliver C 1994 Growth hormone (GH)-releasing hormone secretion is stimulated by a new GH-releasing hexapeptide in sheep. Endocrinology 135 1073-1076.

Hansen TK, Ankersen M, Hansen BS, Raun K, Nielsen KK, Lau J, Peschke B, Lundt BF, Thøgersen H, Johansen NL, Madsen K \& Andersen PH 1998 Novel orally-active growth-hormone secretagogues. Journal of Medicinal Chemistry 41 3705-3714.

Howard A, Feighner S, Cully D, Arena J, Liberator P, Rosenblum C, Hamelin M, Hrenluk D, Palyha O, Anderson J, Paress P, Diaz C, Chou M, Liu K, McKee K, Pong S-S, Chaung L-Y, Elbrecht A, Dashkevicz M, Heavens R, Rigby M, Sirininathsingji D, Dean D, Melillo D, Patchett A, Nargund R, Griffin P, Demartino J, Gupta S, Schaeffer J, Smith R \& Van der Ploeg L 1996 A pituitary gland and hypothalamic receptor that functions in growth hormone release. Science $\mathbf{2 7 3}$ 974-977.

Huhn W, Hartmann M, Pezzoli S \& Thorner M 1993 Twenty-four hour growth hormone $(\mathrm{GH})$-releasing peptide (GHRP) infusion enhances pulsatile GH secretion, and specifically attenuates the response to a subsequent GHRP bolus. Journal of Clinical Endocrinology and Metabolism 76 1202-1208.

Jaffe C, Ho P, Demott-Friberg R, Bowers C \& Barkan A 1993 Effects of a prolonged growth hormone $(\mathrm{GH})$-releasing peptide infusion on pulsatile GH secretion in normal men. Journal of Clinical Endocrinology and Metabolism 77 1641-1647.

Johannsson G, Rosén T, Bosaeus I, Sjöström L \& Bengtsson B1996 Two years of growth hormone $(\mathrm{GH})$ treatment increases bone mineral content and density in hypopituitary patients with adultonset GH deficiency. Journal of Clinical Endocrinology and Metabolism $812865-2873$.

Jørgensen P, Bak B \& Andreassen T 1991 Mechanical properties and biochemical composition of rat cortical femur and tibia after longterm treatment with biosynthetic human growth hormone. Bone $\mathbf{1 2}$ 353-359.
Kassem M, Blum W, Ristelli J, Mosekilde L \& Eriksen E 1993 Growth hormone stimulates proliferation and differentiation of normal human osteoblast-like cells in vitro. Calcified Tissue International 52 222-226.

Kojima M, Hosoda H, Date Y, Nakazato M, Matsuo H \& Kangawa K 1999 Ghrelin is a growth-hormone-releasing acylated peptide from stomach (Letter). Nature 402 656-660.

Laron Z, Frenkel J, Deghenghi R, Anin S, Klinger B \& Sibergeld A 1995 Intranasal administration of the GHRP hexarelin accelerates growth in short children. Clinical Endocrinology 43 631-635

Locke W, Kirgis H, Bowers C \& Abdoh A 1995 Intracerebroventricular growth hormone-releasing peptide-6 stimulates eating without affecting plasma growth hormone responses in rats. Life Sciences 56 $1347-1352$

Mericq V, Cassorla F, Salazar T, Avila A, Iniguez G, Bowers C \& Merriam G 1998 Effects of eight months treatment with graded doses of a growth hormone (GH)-releasing peptide in GH-deficient children. Journal of Clinical Endocrinology and Metabolism $\mathbf{8 3}$ 2355-2360.

Nilsson A, Swolin D, Enerbäck S \& Ohlsson C 1995 Expression of functional growth hormone receptors in cultured human osteoblastlike cells. Journal of Clinical Endocrinology and Metabolism 80 3483-3488.

Ohlsson C, Bengtsson B-Å, Isaksson O, Andreassen T \& Slootweg M 1998 Growth hormone and bone. Endocrine Reviews 19 $55-79$.

Okada K, Ishii S, Minami S, Sugihara H, Shibasaki T \& Wakabayashi I 1996 Intraventricular administration of the growth hormone releasing peptide KP-102 increases food intake in free-feeding rats. Endocrinology 137 5155-5158.

Ong H, McNicoll N, Escher E, Collu R, Deghenghi R, Locatelli V, Ghigo E, Muccioli G, Boghen M \& Nilsson M 1998 Identification of a pituitary growth hormone-releasing peptide (GHRP) receptor subtype by photoaffinity labeling. Endocrinology 139 432-435.

Oscarsson J, Johannsson G, Johansson J-O, Lundberg P-A, Lindstedt G \& Bengtsson B-A 1997 Diurnal variation in serum insulin-like growth factor (IGF)-I and IGF binding protein-3 concentrations during daily subcutaneous injections of recombinant human growth hormone in GH-deficient adults. Clinical Endocrinology 46 63-68.

Raun K, Hansen BS, Johansen NL, Thøgersen H, Madsen K, Ankersen M \& Andersen PH 1998 Ipamorelin, the first selective growth hormone secretagogue. European Journal of Endocrinology 139 $552-561$.

Rosen H, Chen V, Cittadini A, Greenspan S, Douglas P, Moses A \& Beamer W 1995 Treatment with growth hormone and IGF-I in growing rats increases bone mineral content but not bone mineral density. Journal of Bone and Mineral Research $\mathbf{1 0}$ $1352-1358$.

Sandstedt J, Törnell J, Norjavaara E, Isaksson OGP \& Ohlsson C 1996 Elevated levels of growth hormone increase bone mineral content in normal young mice, but not in ovariectomized mice. Endocrinology $1373368-3374$.

Sass D, Jerome C, Bowman A, Bennett-Cain A, LeRoith D \& Epstein S 1997 Short term effects of GH and IGF-1 on cancellous bone formation in rhesus macaque monkeys. Journal of Clinical Endocrinology and Metabolism 82 1202-1209.

Smith R, Van Der Ploeg L, Howard A, Feighner S, Cheng K, Hickey G, Wyvratt MJ, Fischer M, Nargund R \& Patchett A 1998 Peptidomimetic regulation of growth hormone secretion. Endocrine Reviews 18 621-645.

Svensson J, Lönn L, Jansson J-O, Murphy G, Wyss D, Krupa D, Cerchio K, Polvino W, Gertz B, Boseaus I, Sjöström L \& Bengtsson B-A 1998a Two-month treatment of obese subjects with the oral growth hormone $(\mathrm{GH})$ secretagogue MK-677 increases GH 
secretion, fat-free mass, and energy expenditure. Journal of Clinical Endocrinology and Metabolism 83 362-369.

Svensson J, Ohlsson C, Jansson J-O, Murphy G, Wyss D, Krupa D, Cerchio K, Polvino W, Gertz B, Baylink D, Mohan S \& Bengtsson B-A $1998 b$ Treatment with the oral growth hormone secretagogue MK-677 increases markers of bone formation and bone resorption in obese young males. Journal of Bone and Mineral Research $\mathbf{1 3}$ 1158-1166.

Takahashi N, Akatsu T, Udagawa N, Sasaki T, Yamagushi A, Moseley J, Martin T \& Suda T 1988 Osteoblastic cells are involved in osteoclast formation. Endocrinology 123 2600-2602.

Turner R 1995 Effects of short-term space-flight and recombinant human growth hormone $(\mathrm{rhGH})$ on bone growth in young rats. Aviation, Space, and Environmental Medicine 66 763-769.

Verrat-Durebex C, Gaudreau P, Coxam V, Gaumet N \& Alliot J 1999 Peripheral injection of growth hormone stimulates protein intake in aged male and female Lou rats. American Journal of Physiology 276 E1105-E1111.

Windahl SH, Vidal O, Andersson G, Gustafsson JÅ \& Ohlsson C 1999 Increased cortical bone mineral content but unchanged trabecular bone mineral density in female ERbeta $(-/-)$ mice. Journal of Clinical Investigation 104 895-901.

Yeh J, Aloia J \& Chen M 1994 Growth hormone administration potentiates the effect of treadmill exercise on long bone formation but not on the vertebrae in middle-aged rats. Calcified Tissue International 54 38-43.

Received 4 May 1999

Revised manuscript received 13 January 2000 Accepted 8 February 2000 